\section{Kidney \\ Blood Pressure Research}

Kidney Blood Press Res 2015;40:386-394

DOI: 10.1159/000368514

Published online: July 14, 2015

(C) 2015 S. Karger AG, Basel

www.karger.com/kbr

$1423-0143 / 15 / 0404-0386 \$ 39.50 / 0$
Karger

Open access

386

Original Paper

This is an Open Access article licensed under the terms of the Creative Commons AttributionNonCommercial 3.0 Unported license (CC BY-NC) (www.karger.com/OA-license), applicable to the online version of the article only. Distribution permitted for non-commercial purposes only.

\title{
Long-term Outcomes of Parathyroidectomy in Kidney Transplant Recipients with Persistent Hyperparathyroidism
}

\author{
Po-Yu Tseng Wu-Chang Yang Chih-Yu Yang Der-Cherng Tarng \\ Division of Nephrology, Department of Medicine, Taipei Veterans General Hospital and School of \\ Medicine, National Yang-Ming University, Taipei, Taiwan
}

\section{Key Words}

Kidney transplantation - Hyperparathyroidism Parathyroidectomy $\cdot$ Blood pressure $\cdot$ Renal function

\begin{abstract}
Background/Aims: Hyperparathyroidism (HPT) is a common complication of chronic kidney disease and contributes to hypertension and cardiovascular risks. Successful kidney transplantation corrects abnormal mineral metabolism, but persistent HPT is still observed in up to $25 \%$ of patients one year after transplantation despite renal function improvement. The purpose of this study was to examine the long-term effects of parathyroidectomy (PTX) on blood pressure (BP) and graft function in patients with persistent post-transplant HPT. Methods: This is a retrospective study of renal allograft recipients at a single institute. Records from all the patients who received kidney transplantation at the Taipei Veterans General Hospital between 2004 and 2012 were reviewed and enrolled 19 patients who underwent PTX for persistent post-transplant HPT. Preoperative and postoperative clinical and biochemical data were compared. Matched controls $(n=19)$ in the corresponding time span were enrolled for graft function comparisons. Results: The mean systolic BP (127.7 \pm 14.3 to $119.5 \pm 12.7$ $\mathrm{mmHg}, p=0.028,1$ year after PTX; $127.7 \pm 14.3$ to $117 \pm 12.4 \mathrm{mmHg}, p=0.007,2$ years after PTX) and pulse pressure (PP) (51.3 \pm 10.7 to $44.3 \pm 11.6, p=0.0191$ year after PTX; $51.3 \pm 10.7$ to $44.9 \pm 12.5 \mathrm{mmHg}, p=0.028,2$ years after PTX) reduced significantly at 1 year and 2 years of follow-up. However, no significant change of diastolic BP was observed. The improvement of SBP, DBP and PP was not correlated with the reduction of serum calcium level 1 year after PTX. The estimated glomerular filtration rate decreased significantly from $74.0 \pm 20.5 \mathrm{~mL} /$ $\mathrm{min} / 1.73 \mathrm{~m}^{2}$ preoperatively to $68.2 \pm 24.8 \mathrm{~mL} / \mathrm{min} / 1.73 \mathrm{~m}^{2} 12$ months after PTX but recovered at 15 months and lasted to 2 years after PTX. The all-cause hospitalization rate 1 year after PTX tended to be higher than that 1 year before PTX (105.3 versus 47.4 per 100 patient-years; RR, 2.22; 95 \% CI: 0.97-5.54), but there was no significant difference between them. Conclusions:
\end{abstract}




\section{Kidney \\ Blood Pressure Research}

Tseng/Yang/Yang/Tarng: PTX on BP and eGFR in KTRs

Our study demonstrated systolic BP and PP reduced 2 years after PTX and there was no significant difference between the peri-operative all-cause hospitalization rates. In addition, kidney allograft function impaired temporarily 12 months after PTX, but recovered 15 months after PTX.

Copyright (C) 2015 S. Karger AG, Basel

\section{Introduction}

Hyperparathyroidism (HPT) is a common complication of chronic kidney disease (CKD). Elevation of parathyroid hormone (PTH) can be stimulated by hyperphosphatemia, hypocalcemia and the low concentrations of 1,25- dihydroxyvitamin D. Hyperphosphatemia resulting from CKD increases expression of the phosphaturic hormone fibroblast growth factor-23 (FGF23), which further aggravates secondary HPT by reducing 1,25-dihydroxyvitamin D production and directly suppresses parathyroid gland. Even at the early stage of HPT, there is variable under-expression of the calcium-sensing receptor and vitamin D receptor of parathyroid cells, making the parathyroid cells unable to respond appropriately to serum level of calcium and vitamin D [1,2]. Although successful kidney transplantation may correct the abnormal mineral metabolism in the first post-operative month [3, 4], these early favorable effects do not always contribute to rapid normalization of serum PTH level.

Despite renal function restoration, persistent HPT could still be observed in up to $25 \%$ of patients one year after transplantation [5]. There are evidences showing that secondary HPT is associated with increased cardiovascular mortality [6]. Indications for parathyroidectomy (PTX) in kidney transplant recipients include persistent post-transplant HPT combined with severe hypercalcemia, unexplained renal function deterioration, and progressive bone mineral density loss [7-9].

The purpose of this study was to analyze the long-term effect of PTX on the blood pressure and graft function in patients with persistent post-transplant HPT because research data in this respect are still limited with contradictory results.

\section{Materials and Methods}

\section{Study protocol and subjects}

This is a retrospective study on the renal allograft recipients collected at a single institute. Records from all patients subjected to kidney transplantation at the Taipei Veterans General Hospital, Taipei, Taiwan, between January 2004 and December 2012 were reviewed. A total of 255 patients received kidney transplant; 44 among them underwent PTX for persistent post-transplant HPT. The patients who received PTX after graft failure $(n=5)$ and those with missing data $(n=14)$ were excluded from the final analysis. The main cause of the missing data was loss of follow-up. The remaining patients $(n=19), 9$ males and 10 females, comprised the study group. For each of the 19 PTX patients, a renal transplant recipient who didn't receive PTX matched for date of transplantation of the corresponding case was selected as the control group.

We collected demographic information from medical records, including age, gender, body mass index, estimated glomerular filtration rate (eGFR), duration of dialysis before transplant, timing of PTX after transplantation, cause of end stage renal disease (ESRD) of native kidney, comorbidities, anti-hypertensive drugs before PTX, immunosuppressant agents, pre- and post-PTX serum level of PTH, calcium and phosphate. The patients were hospitalized for surgery and were therefore followed up in the out-patient clinic at least every 3 months. BP and biochemistry data were obtained before, 1 year, and 2 years after PTX. The control group was studied in the corresponding time span.

All protocols were approved by the Institutional Review Board of the institute before the study began, and the protocols conformed to the ethical guidelines of the Helsinki Declaration. The need for informed consent was waived because of the retrospective nature of the study. 


\section{Kidney \\ Blood Pressure Research}

Blood pressure measurements and biochemistry examination

Brachial BP was measured with an oscillometric device in seated position after 15 minutes of quiet rest. Pulse pressure (PP) was calculated from the SBP and DBP $(\mathrm{PP}=\mathrm{SBP}-\mathrm{DBP})$. Serum intact $\mathrm{PTH}$ level was measured using an electrochemiluminescence immunoassay. Chronic Kidney Disease Epidemiology Collaboration (CKDEPI) equation was used to estimate the GFR [10].

\section{Statistical ana- lysis \\ Continuous vari-} ables were described as mean \pm standard deviation for normally distributed data, and as median (interquartile range [IQR]) for non-normally distributed data. For continuous variables, paired $t$ test, Mann-Whitney $\mathrm{U}$ test and Pearson correlation were used as appropriate. We used rate ratios (RRs) and $95 \%$ confidence intervals (95\% CIs) to compare the occurrence of hospitalizations in the 1-year period after versus 1 year preceding PTX. Data were analyzed using Statistical Package for the Social Sciences (SPSS) version 18.0 (SPSS, Chicago, USA). All tests were two-tailed and a $p$ value < 0.05 was considered statistically significant.

\section{Results}

We reviewed the records of the study and control groups. The demographics of both groups are listed in Table 1 . The study patients' mean age at the time of PTX was $45.7 \pm 8.2$ years and the mean BMI was $22.9 \pm 2.9\left(\mathrm{Kg} / \mathrm{m}^{2}\right)$. The interval between transplantation and PTX was $1.3 \pm 1.0$ years. The indication of PTX in the study patients was all due to hypercalcemia. Seventeen (89.4\%) patients received subtotal PTX and two $(10.6 \%)$ patients received total PTX. The causes of ESRD of native kidney were diabetic nephropathy $(n=3)$, chronic glomerulonephritis $(n=11)$, chronic interstitial nephritis $(n=1)$, hypertensive nephropathy $(n=3)$ and chronic pyelonephritis $(n=1)$. The most prevalent comorbidities were hypertension (78.9\%), diabetes mellitus (15.8\%), congestive heart failure $(10.5 \%)$ and coronary heart disease (10.5\%). Causes of ESRD, comorbidities, and baseline BP of the control group

Table 1. Characteristics of the patients

\begin{tabular}{|c|c|c|c|}
\hline & Patients & Controls & $p$ Value \\
\hline Number & 19 & 19 & \\
\hline Age (years) & $45.7 \pm 8.2$ & $46.7 \pm 8.8$ & 0.734 \\
\hline Male/Female & $9 / 10$ & $8 / 11$ & 0.744 \\
\hline BMI $\left(\mathrm{Kg} / \mathrm{m}^{2}\right)$ & $22.9 \pm 2.9$ & $24.7 \pm 4.5$ & 0.152 \\
\hline eGFR (mL/min/1.73 m²) & $74.0 \pm 20.5$ & $67.0 \pm 20.1$ & 0.292 \\
\hline Dialysis vintage before transplantation (years) & $8.6 \pm 4.4$ & $5.5 \pm 4.0$ & 0.028 \\
\hline Timing of PTX after transplantation (years) & $1.3 \pm 1.0$ & & 1.000 \\
\hline \multicolumn{4}{|l|}{ Cause of ESRD of native kidney } \\
\hline Diabetic nephropathy (\%) & 15.8 & 15.8 & 1.000 \\
\hline Glomerulonephritis (\%) & 57.9 & 47.4 & 0.516 \\
\hline Interstitial nephropathy (\%) & 5.3 & 10.5 & 1.000 \\
\hline Hypertensive nephropathy (\%) & 15.8 & 21.1 & 1.000 \\
\hline Pyelonephritis (\%) & 5.3 & 5.3 & 1.000 \\
\hline \multicolumn{4}{|l|}{ Comorbidities } \\
\hline Diabetes mellitus (\%) & 15.8 & 15.8 & 1.000 \\
\hline Hypertension (\%) & 78.9 & 73.7 & 1.000 \\
\hline Congestive heart failure $(\%)$ & 10.5 & 5.3 & 1.000 \\
\hline Coronary artery disease (\%) & 10.5 & 10.5 & 1.000 \\
\hline Myocardial infarction (\%) & 5.3 & 0.0 & 1.000 \\
\hline \multicolumn{4}{|l|}{ Maintenance immunosuppressants } \\
\hline Corticosteroid (\%) & 36.8 & 73.7 & 0.022 \\
\hline Cyclosporine A (\%) & 10.5 & 10.5 & 1.000 \\
\hline Tacrolimus (\%) & 84.2 & 78.9 & 1.000 \\
\hline Rapamycin (\%) & 5.3 & 26.3 & 0.180 \\
\hline Mycophenolate mofetil (\%) & 84.2 & 84.2 & 1.000 \\
\hline \multicolumn{4}{|l|}{ Anti-hypertension drug before surgery } \\
\hline ACEI/ARB (\%) & 31.6 & 31.6 & 1.000 \\
\hline ССВ $(\%)$ & 68.4 & 36.8 & 0.051 \\
\hline Beta-blocker (\%) & 42.1 & 42.1 & 1.000 \\
\hline Systolic blood pressure (mmHg) & $127.7 \pm 14.3$ & $130.1 \pm 21.8$ & 0.695 \\
\hline Diastolic blood pressure (mmHg) & $76.4 \pm 9.18$ & $79.4 \pm 11.2$ & 0.371 \\
\hline Pulse pressure (mmHg) & $51.3 \pm 10.7$ & $50.7 \pm 17.2$ & 0.893 \\
\hline *iPTH $(\mathrm{pg} / \mathrm{mL})$ & $327(163-476)$ & & \\
\hline $\mathrm{Ca}(\mathrm{mg} / \mathrm{dL})$ & $11.7 \pm 0.8$ & $9.6 \pm 0.5$ & $<0.001$ \\
\hline $\mathrm{P}(\mathrm{mg} / \mathrm{dL})$ & $2.3 \pm 0.7$ & $2.9 \pm 0.5$ & 0.007 \\
\hline
\end{tabular}




\section{Kidney \\ Blood Pressure Research}

Table 2. Laboratory data, blood pressure, and eGFR before and after PTX

\begin{tabular}{lccccc}
\hline \multirow{2}{*}{\multicolumn{1}{c}{ Variable }} & Pre-PTX & \multicolumn{2}{c}{ Post-PTX } & \multicolumn{2}{c}{$p$ Value } \\
\cline { 2 - 6 } & Baseline & 1 year (Y1) & 2 years (Y2) & $\begin{array}{c}\text { Baseline } \\
\text { vs. Y1 }\end{array}$ & $\begin{array}{c}\text { Baseline } \\
\text { vs. Y2 }\end{array}$ \\
\hline Systolic blood pressure (mmHg) & $127.7 \pm 14.3$ & $119.5 \pm 12.7$ & $117 \pm 12.4$ & 0.028 & 0.007 \\
Diastolic blood pressure (mmHg) & $76.4 \pm 9.2$ & $75.2 \pm 9.2$ & $72.1 \pm 7.4$ & 0.613 & 0.077 \\
Pulse pressure (mmHg) & $51.3 \pm 10.7$ & $44.3 \pm 11.6$ & $44.9 \pm 12.5$ & 0.019 & 0.028 \\
Number of anti-hypertensive drugs & $1.4 \pm 0.9$ & $1.0 \pm 1.0$ & $0.7 \pm 1.0$ & $<0.001$ & 0.012 \\
* iPTH (pg/mL) & $327(163-476)$ & $35.8(11.4-81.3)$ & & $<0.001$ & \\
Ca (mg/dL) & $11.7 \pm 0.8$ & $9.4 \pm 0.6$ & $9.1 \pm 0.7$ & $<0.001$ & $<0.001$ \\
P (mg/dL) & $2.3 \pm 0.7$ & $3.0 \pm 0.1$ & $3.1 \pm 0.7$ & $<0.001$ & $<0.001$ \\
Ca $\times$ P & $26.5 \pm 8.1$ & $28.3 \pm 5.1$ & $28.4 \pm 5.8$ & 0.280 & 0.374 \\
eGFR (mL/min/1.73 m $\left.{ }^{2}\right)$ & $74.0 \pm 20.5$ & $68.2 \pm 24.8$ & $70.3 \pm 27.3$ & 0.010 & 0.276 \\
\hline
\end{tabular}

Data are presented as mean \pm SD or *median (IQR). Abbreviations: PTX, parathyroidectomy; eGFR, estimated glomerular filtration rate by the CKD-EPI formula; Ca, calcium; $\mathrm{P}$, phosphate.

were similar to those of the study group. As compared to the control group, serum calcium was significant higher and serum phosphate was lower in the study group.

The serial changes of BP before PTX, 1 year, and 2 years after PTX in the study group are listed in Table 2. Compared with their baseline status (pre-PTX), SBP ( $p=0.028$, in 1 year; $p$ $=0.007$ in 2 years $)$ and PP ( $p=0.019$ in 1 year; $p=0.028$ in 2 years) decreased significantly, while DBP remained unchanged. The number of anti-hypertensive drugs taken was reduced 1 and 2 years after PTX ( $p<0.001$ in 1 year; $p=0.012$ in 2 years). There was no correlation between the change of SBP, DBP and PP and the change of serum calcium, phosphate or iPTH level 1 year after PTX (Figure 1).

A significant reduction of the serum level of iPTH (reference range: 15.0-68.3 pg/mL) and calcium (reference range: $8.4-10.6 \mathrm{mg} / \mathrm{dL}$ ) were observed after PTX in the study group. Serum phosphate level (reference range: $2.1-4.7 \mathrm{mg} / \mathrm{dL}$ ), conversely, increased significantly. Figure 2 demonstrates that PTX may lead to temporary kidney allograft dysfunction, while the graft function was steady in the control group in the corresponding period. Graft function declined significantly 12 months after PTX. However, it improved 15 months after PTX and showed no significant difference from baseline. The change of serum calcium during the first year was not related to the change of eGFR. As for the time period between 1 year after PTX and 2 years after PTX, there was still no correlation between the change of calcium level and the change of eGFR (Figure 3).

A total of 20 all-cause hospitalizations occurred among 19 individuals within one year after PTX. The average annual hospitalization rate was 1.05 per person. All-cause hospitalizations were higher by $122 \%$ compared with the prior one year before PTX (105.3 versus 47.4 per 100 patient-years; RR, 2.22; $95 \%$ CI: 0.97-5.54, Figure 4). Only one hospitalization after PTX was due to hypocalcemia.

Fig. 1. Pearson correlations between the change of blood pressure (BP) (\%) and the change of serum calcium, phosphate, and intact parathyroid hormone (iPTH) (\%) 1 year after parathyroidectomy (PTX). (A) the change of systolic BP (SBP) after PTX (\%) vs. the change of serum calcium after PTX(\%) $(\mathrm{r}=0.100, p=$ 0.684), (B) the change of diastolic BP (DBP) after PTX (\%) vs. the change of serum calcium after PTX (\%) ( $r$ $=0.064, p=0.794)$, (C) the change of pulse pressure (PP) after PTX (\%) vs. the change of serum calcium after PTX (\%) ( $r=0.012, p=0.960)$, (D) the change of SBP after PTX (\%) vs. the change of serum phosphate (\%) $(\mathrm{r}=0.011, p=0.966)$, (E) the change of DBP after PTX (\%) vs. the change of serum phosphate after PTX (\%) $(\mathrm{r}=0.051, p=0.836)$, (F) the change of PP after PTX (\%) vs. the change of serum phosphate after PTX (\%) $(\mathrm{r}=-0.010, p=0.969),(\mathrm{G})$ the change of SBP after PTX (\%) vs. the change of serum iPTH (\%) $(\mathrm{r}=-0.033$, $p=0.892)$, (H) the change of DBP after PTX (\%) vs. the change of serum iPTH after PTX (\%) ( $\mathrm{r}=0.098, p$ $=0.689)$, (I) the change of PP after PTX (\%) vs. the change of serum iPTH after PTX (\%) $(\mathrm{r}=-0.0128, p=$ $0.601)$.

$\nabla$ 


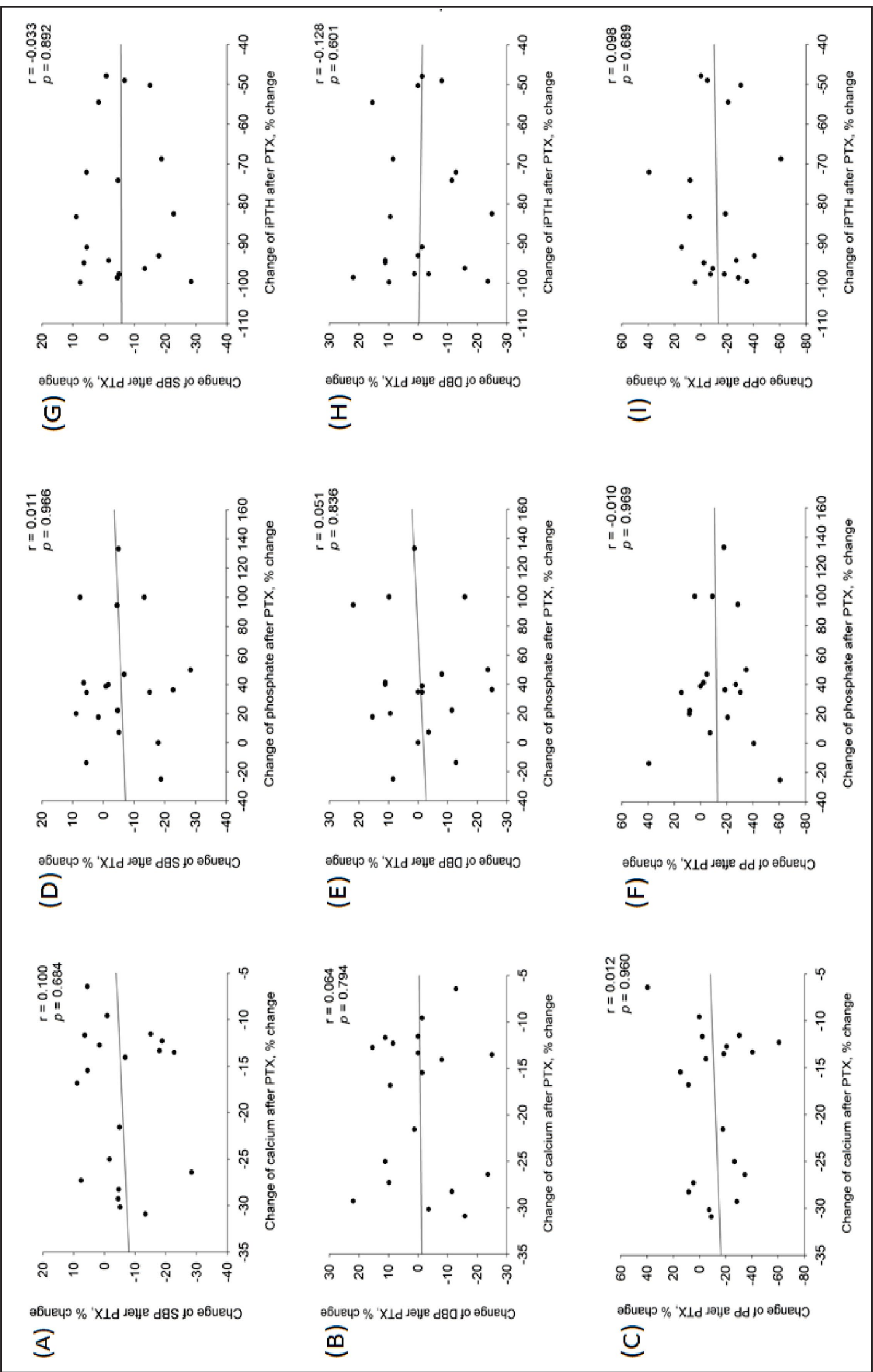




\section{Kidney \\ Blood Pressure \\ Research}

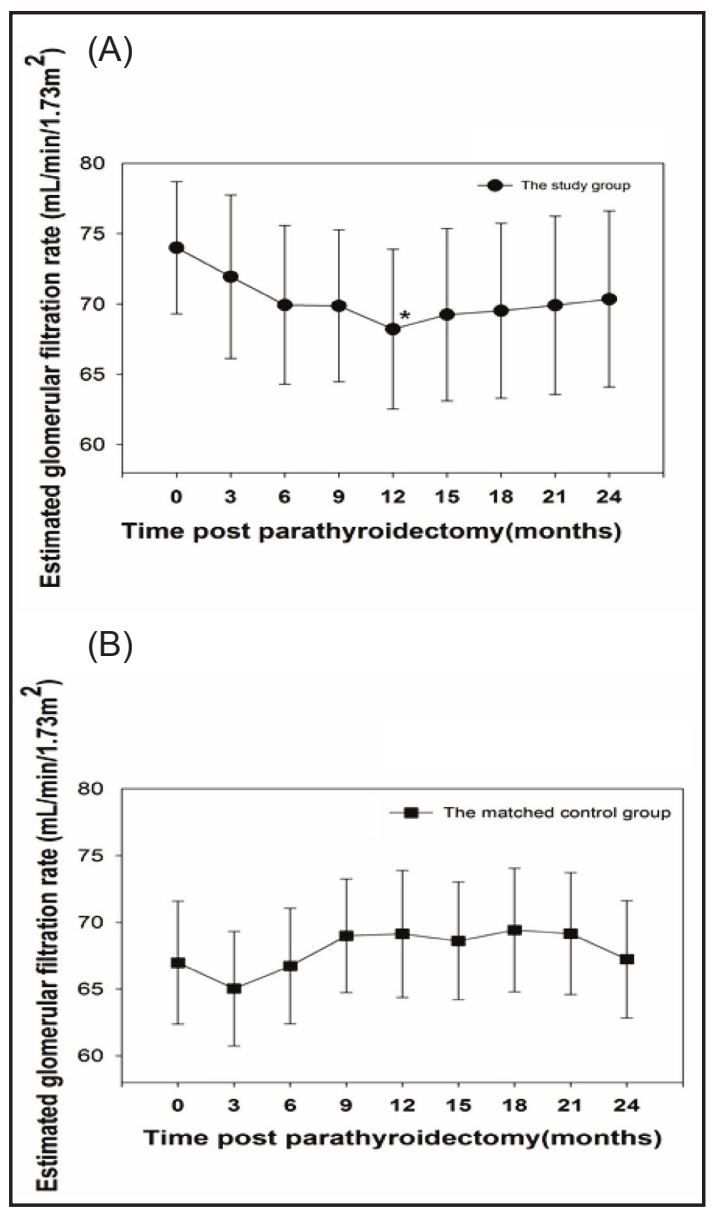

Fig. 2. (A) Glomerular filtration rate estimated by the CKD-EPI formula (eGFR) declined 1 year after parathyroidectomy (PTX) in kidney transplant recipients with persistent hyperparathyroidism $(74.0 \pm 20.5$ to $68.2 \pm 24.8, p<0.010)$, but it recovered 15 months after PTX $(74.0 \pm 20.5$ to $69.2 \pm 26.7, p=$ 0.099). ${ }^{*} p<0.05$, (B) eGFR of the matched control group remained steady.

\section{Discussion}

This study demonstrated an enduring effect beyond 2 years of PTX in reducing SBP and $\mathrm{PP}$ as well as the requirement of anti-hypertensive drugs in patients with persistent post-transplant HPT. Several small-scale studies have examined the effect of PTX on BP in patients with secondary HPT with contradictory results. A previous study disclosed a significant decrease of SBP and DBP after PTX in 30 dialysis patients with HPT [11], while others failed to find that PTX could correct hypertension in primary HPT [12] . Few studies have focused on the subgroup of patients

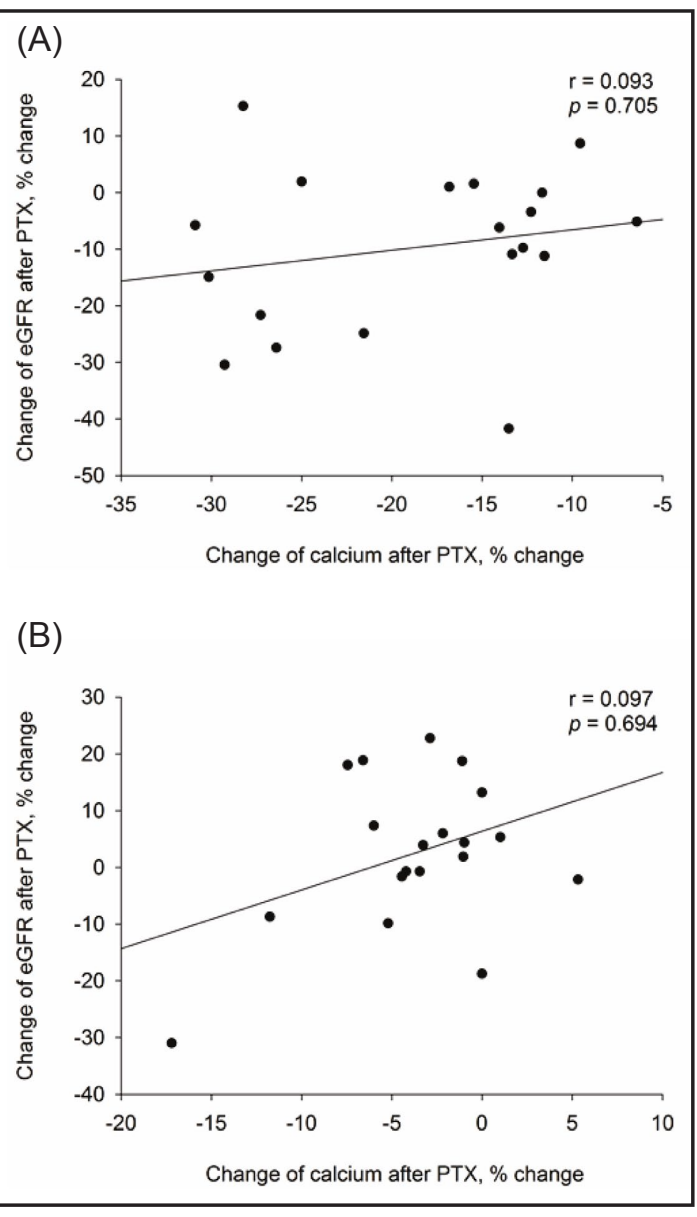

Fig. 3. Pearson correlations between the change of estimated glomerular filtration rate (eGFR) (\%) and the change of serum calcium (\%) after parathyroidectomy (PTX). (A) baseline vs. 1 year after PTX ( $r=0.093, p=0.705)$, (B) 1 year after PTX vs. 2 years after PTX ( $r=0.097, p=0.694)$.

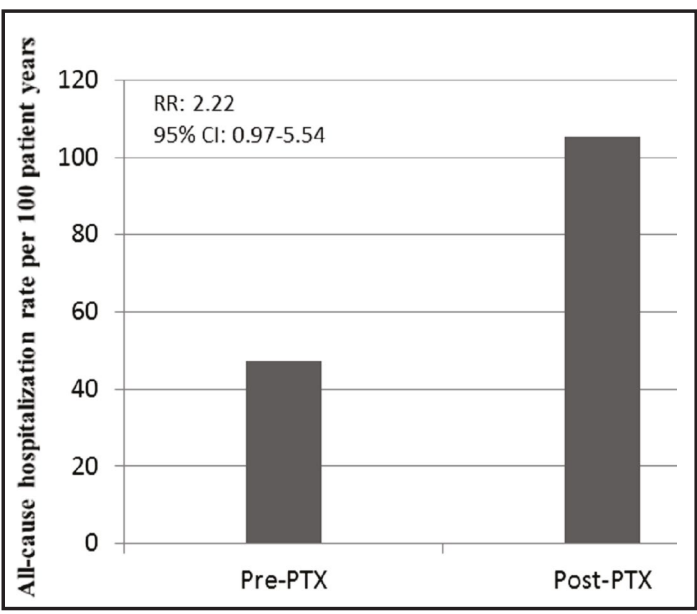

Fig. 4. All-cause hospitalization rate 1 year before and 1 year after parathyroidectomy (PTX). 


\section{Kidney Blood Pressure Research}

Kidney Blood Press Res 2015;40:386-394

DOI: 10.1159/000368514

Published online: July 14, 2015

(C) 2015 S. Karger AG, Basel

www.karger.com/kbr

Tseng/Yang/Yang/Tarng: PTX on BP and eGFR in KTRs

having persistent post-transplant HPT, except a retrospective study that demonstrated the significant decrease of SBP and DBP in kidney transplant recipients 6 months after PTX [13, 14]. Our study was the first one to further examine the long-term BP alteration after PTX.

There are some hypotheses to explain the reduction of blood pressure after PTX. One possible mechanism is persistent HPT-related hypercalcemia which is linked to development of vascular calcification [6] and is assumed to stiffen the vasculature and impair the arterial distensibility, leading to high PP, which is as an indicator of arterial stiffness. This hypothesis was proven by a study showing that intradialytic hypotension was significantly improved after PTX in maintenance hemodialysis patients with secondary HPT [15], in agreement with our findings of the successful correction of hypercalcemia after PTX. In animal and human studies, acute exposure of PTH seemed to reduce BP as a result of the vasodilatory effect [16, 17], whereas chronic exposure could induce hypertension through inducing the accumulation of calcium in vascular smooth muscle cells $[16,18]$. However, we failed to demonstrate the correlation between the reduction of serum calcium or iPTH level and the change of the SBP, DBP and PP after PTX. Our findings suggest the possibilities of other unknown mechanisms that might contribute to the improvement of BP control beyond hypercalcemia correction. Further prospective trials are warranted.

There are other hypotheses to explain the association between PTX and reduction of BP. A previous study has found that PTH directly stimulated the activity of the renin-angiotensin-aldosterone system to increase BP [19]. In their studies, they provided that PTX reduced BP by suppressing serum levels of renin and aldosterone in primary HPT patients. In a recent animal study, high phosphate diet resulted in elevated BP through PTH mediated renin stimulation, in concordance with the previous finding [20]. Endothelium is another target of PTH with potential alteration on BP. Endothelial dysfunction is related to PTH levels and elevated PTH compromises the elastic properties of the arterial wall [21]. Over responsiveness of vasoactive hormones in the presence of HPT was assumed by a study to account for the high BP [22]. Our study further demonstrated that the BP-lowering effect of PTX was able to last for 2 years.

We also observed a normalization of serum phosphate after PTX. Hypophosphatemia is noted temporarily in up to $90 \%$ of the patients in the early post-transplant period [23]. According to previous studies, FGF23 levels remain increased in renal transplant recipients at early post-transplant period $[23,24]$. Therefore, FGF23 and persistent HPT may act synergistically to increase the effect of phosphaturia. In our study, low level of serum phosphate after transplantation and normalization of it after PTX may further support this hypothesis.

The current recommendation for persistent post-transplant HPT is to closely observe and frequently monitor until spontaneous resolution. The indications for PTX include persistent hypercalcemia, symptomatic hyperparathyroid bone disease, rapidly worsening vascular calcification, and spontaneous fractures in the presence of HPT [7-9]. In our study, the indication for PTX of the study patients was all due to hypercalcemia, suggesting a tertiary HPT status. However, the decision of receiving PTX in clinical practice is still very difficult because the impact of PTX on allograft function is contradictory.

A previous study on 32 patients who received PTX for post-transplant HPT has shown that eGFR continued to decline for two months after PTX but then began to recover toward pre-PTX level 12 months after PTX. In other words, the post-PTX GFR decline was temporary and would eventually recover to pre-PTX levels [25]. However, another study reviewed 32 patients subjected to PTX at least 9 months after transplantation and found significant deterioration of graft function 6 months after PTX [13]. In their study, long-term stabilization was not observed due to a short follow-up period. In addition, Kandil et al. retrospectively analyzed 49 patients who received PTX after kidney transplantation and found that PTX contributed to GFR decline after 3 years of follow-up. However, the 3-year graft survival in their study showed no statistical difference between groups [26]. In our study, we found that graft function deteriorated temporarily 12 months after PTX but recovered to the baseline 15 months after PTX. On the other hand, the graft function of the control group was steady in the corresponding period. The mechanism to link the early graft dysfunction and PTX is not completely understood, although some possibilities have been proposed. In an animal mo- 


\section{Kidney \\ Blood Pressure Research}

del, PTH has shown to have significant vasodilatory effects on preglomerular vessels while at the same time efferent arterioles are constricted secondary to renin release [27]. The acute deterioration of renal function owing to the reverse of glomerular hyperfiltration means reduced renal perfusion following PTX. However, the hemodynamic correction should attenuate hyperfiltration injury and progression of kidney injury on a long-term basis. Our finding of temporary graft function impairment after PTX was consistent with this hypothesis. After an initial deterioration, renal function showed a steady improvement with time approaching to the baseline. Additionally, PTX normalized serum calcium level and decreased vasoconstriction and nephrocalcinosis mediated by hypercalcemia. Therefore, graft function improved once hypercalcemia was corrected after PTX. However, the change of serum calcium was not correlated with the change of eGFR in our cohort. There might be other mechanisms responsible for the improvement of the graft function after PTX, which deserves further prospective research.

Few studies have comprehensively evaluated the risk associated with PTX. In one large study using USRDS data and observed the higher 30-day mortality compared with those who did not ( $3.1 \%$ versus $1.2 \%$ ) in dialysis patients; this elevated risk lasted to 90 days and inverted after 90 days [28]. A recent nationwide cohort of patients on hemodialysis found that all-cause hospitalizations one year after PTX were higher by $39 \%$ compared to one year prior to PTX. [29]. In our study, all-cause annual hospitalization rate before and after PTX showed no significant difference. Our study is the first to evaluate the peri-operative hospitalization rate in renal transplant recipients.

\section{Conclusion}

Persistent post-transplant HPT can be corrected by PTX. Our findings demonstrated that SBP and PP were reduced 2 years after PTX and there was no significant difference between the pre-operative and post-operative all-cause hospitalization rates. In spite of temporary kidney allograft dysfunction that occurred 12 months after PTX, the graft function eventually recovered 15 months after PTX.

\section{Disclosure Statement}

All authors declare that they have no conflict of interest.

\section{References}

1 Cunningham J, Locatelli F, Rodriguez M: Secondary hyperparathyroidism: pathogenesis, disease progression, and therapeutic options. Clin J Am Soc Nephrol 2011;6:913-921.

2 Latus J, Lehmann R, Roesel M, Fritz P, Braun N, Ulmer C, Steurer W, Biegger D, Ott G, Dippon J, Alscher MD, Kimmel M: Analysis of alpha-klotho, fibroblast growth factor-, vitamin-D and calcium-sensing receptor in 70 patients with secondary hyperparathyroidism. Kidney Blood Press Res 2013;37:84-94.

3 Messa P, Sindici C, Cannella G, Miotti V, Risaliti A, Gropuzzo M, Di Loreto PL, Bresadola F, Mioni G: Persistent secondary hyperparathyroidism after renal transplantation. Kidney Int 1998;54:1704-1713.

4 Bonani M, Rodriguez D, Fehr T, Mohebbi N, Brockmann J, Blum M, Graf N, Frey D, Wuthrich RP: Sclerostin blood levels before and after kidney transplantation. Kidney Blood Press Res 2014;39:230-239.

5 Evenepoel P, Claes K, Kuypers D, Maes B, Bammens B, Vanrenterghem Y: Natural history of parathyroid function and calcium metabolism after kidney transplantation: a single-centre study. Nephrol Dial Transplant 2004;19:1281-1287.

6 Moe SM, Chen NX: Mechanisms of vascular calcification in chronic kidney disease. J Am Soc Nephrol 2008;19:213-216.

7 Triponez F, Clark OH, Vanrenthergem Y, Evenepoel P: Surgical treatment of persistent hyperparathyroidism after renal transplantation. Ann Surg 2008;248:18-30. 


\section{Kidney \\ Blood Pressure Research}

Kidney Blood Press Res 2015;40:386-394

DOI: 10.1159/000368514

Published online: July 14, 2015

(C) 2015 S. Karger AG, Basel

www.karger.com/kbr

Tseng/Yang/Yang/Tarng: PTX on BP and eGFR in KTRs

8 National Kidney F: K/DOQI clinical practice guidelines for bone metabolism and disease in chronic kidney disease. Am J Kidney Dis 2003;42:S1-201.

9 Salmhofer H, Franzen M, Hitzl W, Koller J, Kreymann B, Fend F, Hauser-Kronberger C, Heemann U, Berr F, Schmaderer C: Multi-modal treatment of calciphylaxis with sodium-thiosulfate, cinacalcet and sevelamer including long-term data. Kidney Blood Press Res 2013;37:346-359.

10 Levey AS, Stevens LA, Schmid CH, Zhang YL, Castro AF, 3rd, Feldman HI, Kusek JW, Eggers P, Van Lente F, Greene T, Coresh J: A new equation to estimate glomerular filtration rate. Ann Intern Med 2009;150:604-612.

11 Lin HC, Chen CL, Lin HS, Chou KJ, Fang HC, Liu SI, Hsu CY, Huang WC, Huang CW, Huang CK, Chang TY, Chang YT, Lee PT: Parathyroidectomy improves cardiovascular outcome in nondiabetic dialysis patients with secondary hyperparathyroidism. Clin Endocrinol (Oxf) 2014;80:508-515.

12 Rydberg E, Birgander M, Bondeson AG, Bondeson L, Willenheimer R: Effect of successful parathyroidectomy on 24-hour ambulatory blood pressure in patients with primary hyperparathyroidism. Int J Cardiol 2010;142:15-21.

13 Evenepoel P, Claes K, Kuypers D, Maes B, Vanrenterghem Y: Impact of parathyroidectomy on renal graft function, blood pressure and serum lipids in kidney transplant recipients: a single centre study. Nephrol Dial Transplant 2005;20:1714-1720.

14 Jones DB, Jones JH, Lloyd HJ, Lucas PA, Wilkins WE, Walker DA: Changes in blood pressure and renal function after parathyroidectomy in primary hyperparathyroidism. Postgrad Med J 1983;59:350-353.

15 Shih CJ, Tarng DC, Yang WC, Yang CY: Parathyroidectomy reduces intradialytic hypotension in hemodialysis patients with secondary hyperparathyroidism. Kidney Blood Press Res 2013;37:323-331.

16 Massry SG, Iseki K, Campese VM: Serum calcium, parathyroid hormone, and blood pressure. Am J Nephrol 1986;6 Suppl 1:19-28.

17 Jespersen B, Randlov A, Abrahamsen J, Fogh-Andersen N, Kanstrup IL: Effects of PTH(1-34) on blood pressure, renal function, and hormones in essential hypertension: the altered pattern of reactivity may counteract raised blood pressure. Am J Hypertens 1997;10:1356-1367.

18 Hulter HN, Melby JC, Peterson JC, Cooke CR: Chronic continuous PTH infusion results in hypertension in normal subjects. J Clin Hypertens 1986;2:360-370.

19 Kovacs L, Goth MI, Szabolcs I, Dohan O, Ferencz A, Szilagyi G: The effect of surgical treatment on secondary hyperaldosteronism and relative hyperinsulinemia in primary hyperparathyroidism. Eur J Endocrinol 1998;138:543-547.

20 Bozic M, Panizo S, Sevilla MA, Riera M, Soler MJ, Pascual J, Lopez I, Freixenet M, Fernandez E, Valdivielso JM: High phosphate diet increases arterial blood pressure via a parathyroid hormone mediated increase of renin. J Hypertens 2014;32:1822-1832.

21 Barenbrock M, Hausberg M, Kosch M, Kisters K, Hoeks AP, Rahn KH: Effect of hyperparathyroidism on arterial distensibility in renal transplant recipients. Kidney Int 1998;54:210-215.

22 Schiffl H, Lang SM: Hypertension Secondary to PHPT: Cause or Coincidence? Int J Endocrinol 2011;2011:974647.

23 Evenepoel P, Naesens M, Claes K, Kuypers D, Vanrenterghem Y: Tertiary 'hyperphosphatoninism' accentuates hypophosphatemia and suppresses calcitriol levels in renal transplant recipients. Am J Transplant 2007;7:1193-1200.

24 Evenepoel P, Meijers BK, de Jonge H, Naesens M, Bammens B, Claes K, Kuypers D, Vanrenterghem Y: Recovery of hyperphosphatoninism and renal phosphorus wasting one year after successful renal transplantation. Clin J Am Soc Nephrol 2008;3:1829-1836.

25 Parikh S, Nagaraja H, Agarwal A, Samavedi S, Von Visger J, Nori U, Andreoni K, Pesavento T, Singh N: Impact of post-kidney transplant parathyroidectomy on allograft function. Clin Transplant 2013;27:397-402.

26 Kandil E, Florman S, Alabbas H, Abdullah O, McGee J, Noureldine S, Slakey D, Zhang R: Exploring the effect of parathyroidectomy for tertiary hyperparathyroidism after kidney transplantation. Am J Med Sci 2010;339:420-424.

27 Massfelder T, Parekh N, Endlich K, Saussine C, Steinhausen M, Helwig JJ: Effect of intrarenally infused parathyroid hormone-related protein on renal blood flow and glomerular filtration rate in the anaesthetized rat. Br J Pharmacol 1996;118:1995-2000.

28 Kestenbaum B, Andress DL, Schwartz SM, Gillen DL, Seliger SL, Jadav PR, Sherrard DJ, Stehman-Breen C: Survival following parathyroidectomy among United States dialysis patients. Kidney Int 2004;66:2010-2016.

29 Ishani A, Liu J, Wetmore JB, Lowe KA, Do T, Bradbury BD, Block GA, Collins AJ: Clinical outcomes after parathyroidectomy in a nationwide cohort of patients on hemodialysis. Clin J Am Soc Nephrol 2015;10:9097. 